\title{
Association of sleep disorders with subfoveal choroidal thickness in preschool children
}

\author{
Shiya Shen ${ }^{1} \cdot$ Xiaoxiao $\mathrm{Li}^{1} \cdot \mathrm{Rui}_{\mathrm{Li}}{ }^{1} \cdot$ Dan Huang $^{2} \cdot \mathrm{Xiaoyan}_{\mathrm{Zhao}}{ }^{1} \cdot \mathrm{Xiaohan}_{\mathrm{Zhang}}{ }^{3} \cdot \mathrm{Qingfeng} \mathrm{Hao}^{1} \cdot$ Qigang Sun $^{4}$. \\ Haohai Tong ${ }^{1} \cdot$ Xinyu Zheng ${ }^{5} \cdot$ Yelongzi $\mathrm{CaO}^{5} \cdot$ Shuning $\mathrm{Liu}^{5} \cdot$ Hui Zhu $\mathbb{D}^{1} \cdot \mathrm{Hu}$ Liu $\mathbb{D}^{1}$
}

Received: 10 May 2020 / Revised: 29 January 2021 / Accepted: 22 February 2021 / Published online: 11 March 2021

(c) The Author(s) 2021. This article is published with open access

\begin{abstract}
Objective To explore the association between sleep disorders and subfoveal choroidal thickness (SFCT) in preschool children.

Methods In this population-based cross-sectional study, children aged 60-72 months were measured for SFCT using spectral-domain optical coherence tomography (SD-OCT) and for sleep disorders using the Chinese version of Children's Sleep Habits Questionnaire (CSHQ). Multiple linear regression analyses were performed to assess the association between sleep disorders and SFCT.

Results A total of 1337 children (mean (SD) age: 66.88 (3.41) months) were included in the analyses. In multivariable linear analysis, a higher total CSHQ score (indicating higher likelihood of sleep disorders) was associated with a thinner subfoveal choroid (beta, $-0.070 ; 95 \% \mathrm{CI},-0.141$ to $-0.001 ; P=0.046)$. When each of eight CSHQ subscale scores was analysed by the multivariable model, only the Daytime Sleepiness subscale score was negatively associated with the SFCT (beta, $-0.115 ; 95 \% \mathrm{CI},-0.183$ to $-0.046 ; P=0.001)$. The children with clinically significant daytime sleepiness $(n=364$, $27.2 \%$ ) had significantly thinner subfoveal choroid than other children (295.47 vs. $308.52 \mu \mathrm{m}, P=0.007)$.

Conclusions Only daytime sleepiness was significantly associated with SFCT in preschool children in this study. The potential relationship between sleep disorders during childhood and children's ocular development needs further research.
\end{abstract}

These authors contributed equally: Shiya Shen, Xiaoxiao Li, Rui Li

Supplementary information The online version contains supplementary material available at https://doi.org/10.1038/s41433021-01489-y.

$\triangle$ Hui Zhu

zhny1125@njmu.edu.cn

$\triangle \mathrm{Hu}$ Liu

liuhu@njmu.edu.cn

1 Department of Ophthalmology, The First Affiliated Hospital with Nanjing Medical University, Nanjing, China

2 Department of Child Healthcare, The First Affiliated Hospital with Nanjing Medical University, Nanjing, China

3 Department of Ophthalmology, Wuxi Children's Hospital, Wuxi, China

4 Department of Ophthalmology, Maternal and Child Healthcare Hospital of Yuhuatai District, Nanjing, China

5 The Fourth School of Clinical Medicine of Nanjing Medical University, Nanjing, China

\section{Introduction}

In the past decades, children's sleep habits have changed substantially, and sleep disorders have become very common [1]. The literature has reported that about $20-60 \%$ of preschool children have at least one sleep disorder [1-4]. As an essential physiological phenomenon accompanied by changes in various physiological functions, sleep has significant influence on children's memory, cognition, behaviour, psychosocial functioning and physical development [5, 6]. Inadequate and disordered sleep has been acknowledged to be associated with numerous impairments and diseases, such as injury [7], depression, anxiety [8], autism, attention-deficit/hyperactivity disorder [9], weight gain and obesity [10], diabetes, heart disease and dementia [11, 12].

The choroid is a heterogeneous tissue consisting of blood vessels and stroma. As the main source of ocular blood flow, its structural and functional integrity is important for ocular development and health. Changed choroidal thickness has been found in various diseases [13, 14]. In 
addition, choroidal thickness has been shown to be associated with sleep disorders in adult. A meta-analysis suggested that subfoveal choroidal thickness (SFCT) was significantly reduced in adult patients with different severities of obstructive sleep apnea syndrome (OSAS) [15]. The mechanism of reduced choroidal thickness in OSAS might be related to hypoxia induced by OSAS, but has not been verified yet.

The effect of sleep disorders on children's choroidal thickness remains unknown. Previous studies showed that changes in choroidal thickness is closely associated with the development of myopia and myopic maculopathy [16-20]. In addition, sleep disorders were also found to be associated with myopia in children [21]. Therefore, we speculate that there might be a relationship between sleep disorders and choroidal thickness in children. To test this hypothesis, we analysed the data from the population-based Nanjing Eye Study (NES) to assess the association of sleep disorders with SFCT in preschool children aged 60-72 months.

\section{Materials and methods}

\section{Study population}

The study participants are from the population-based Nanjing Eye Study (NES). The details of NES have been reported before [22-24]. In brief, all children born in Yuhuatai District, Nanjing, China between September 2011 and August 2012, and entering kindergartens in Yuhuatai District, were invited to participate in the NES. All participants underwent a comprehensive eye examination annually since 2015 . The data presented in this paper were obtained in 2017, when these children were 60-72 months old. Children with history of or ongoing ocular diseases, history of ocular surgery, or congenital malformations were excluded from this study. The study was approved by the Ethics Committee of The First Affiliated Hospital with Nanjing Medical University and followed the tenets of the Declaration of Helsinki. Written informed consent was obtained from the parents or legal guardians of all participants. Oral assent was obtained from all children right before the examination.

\section{Ocular and anthropometric examinations}

A comprehensive eye examination for all participants was performed by a team composed of six trained ophthalmologists and four optometrists, including visual acuity, anterior segment, posterior segment, refraction, stereoacuity test, ocular alignment and motility, ocular biometric parameters, intraocular pressure, accommodative response and optical coherence tomography. Lenstar LS900 (Haag-Streit
Koeniz, Switzerland) was used to measure ocular biometric parameters under non-cycloplegic conditions, including axial length (AL), corneal radius of curvature (CR), central corneal thickness, anterior chamber depth, lens thickness. All these measurements were taken five times and then averaged. Retinoscopy was performed after cycloplegia to measure refraction. One drop of topical $1.0 \%$ cyclopentolate (Cyclogyl, Alcon Pharmaceuticals) was administered to each eye twice at a 5 min interval. After $15 \mathrm{~min}$, a third drop of cyclopentolate was administered if the pupil size was $<6$ $\mathrm{mm}$ or the pupillary light reflex was still present. The spherical equivalent (SE) was calculated as the sphere power plus half of the cylinder power. Anthropometric parameters included height and weight, which were measured without shoes and heavy clothing. Body mass index was defined as body weight divided by the square of body height and was expressed in units of $\mathrm{kg} / \mathrm{m}^{2}$.

The choroid was imaged using spectral-domain optical coherence tomography (SD-OCT) (Cirrus HD-OCT 5000; Carl Zeiss Meditec, Inc., Dublin, CA, USA) with the enhanced depth imaging system under a cross line scan pattern focused on the fovea. Each line was composed of 8 B-scans consisting of 1024 A-scans. Each scan was required to have a scan signal intensity $\geq 6$ and captured in a similar time period within a day without pupil dilation. SFCT was defined as the distance from the outer border of the retinal pigment epithelium to the inner border of the sclera running through the centre of the fovea, and was measured by a trained examiner using a manual calliper of the device software (Fig. 1). The centre of the fovea was identified on the scan line with the deepest foveal depression and a pronounced specular bottom reflex. Choroidal images and measurements were obtained from both eyes. Intra-grader reliability for the SFCT was high with intraclass correlation of 0.963 based on 300 eyes with SFCT measured twice.

\section{Questionnaires}

A comprehensive questionnaire was distributed to a parent of each participant to collect information, mainly including history of pregnancy and birth, home environment, daily activities, and sleep disorders. Children's daily activities per week were divided into five activities: (1) outdoor activities; (2) studying and reading for school assignments; (3) reading for pleasure; (4) using a computer or electronic products/ playing video games; (5) watching television. The dioptrehour (Dh) was defined as: $\mathrm{Dh}=3 \times$ (hours of studying and reading for school + hours of reading for pleasure) $+2 \times$ (video game/computer/electronic product hours) $+1 \times$ (hours of watching television) [25, 26]. The well-validated Chinese version of Children's Sleep Habits Questionnaire (CSHQ) was used to assess sleep disorders [27-29]. This questionnaire includes total of 33 items, covering 


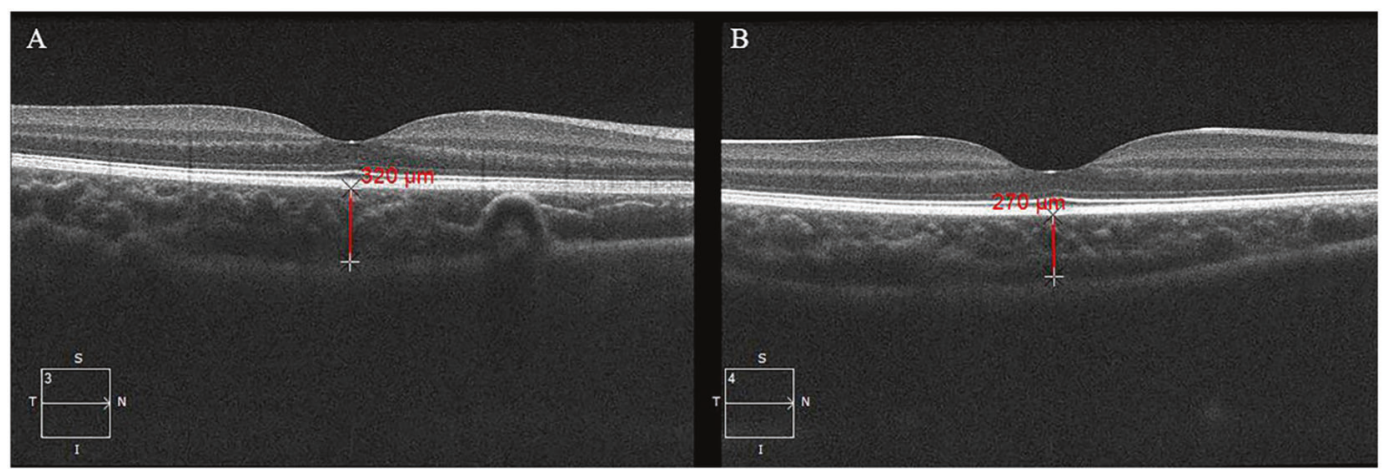

Fig. 1 Choroidal thickness measurement. Subfoveal choroidal thickness (red line) was defined as the distance from the outer border of the retinal pigment epithelium to the inner border of the sclera running through the centre of the fovea. A Subfoveal choroidal thickness in a normal child. B Subfoveal choroidal thickness in a child with daytime sleepiness.

8 subscales: Bedtime Resistance, Sleep Onset Delay, Sleep Duration, Sleep Anxiety, Night Wakings, Parasomnias, Sleep Disordered Breathing and Daytime Sleepiness. Parents were asked to rate the frequency for each item based on the observation of the children in the past recent week or a typical week on a 3-point Likert Scale: "usually" (5-7 times per week), "sometimes" (2-4 times per week) and "rarely" (0-1 time per week). The subscale scores and total CSHQ score were calculated following standard scoring algorithm. The total CSHQ score ranges from 33 to 99, with higher total score indicating greater sleep problems [30]. A total score $>41$ has been suggested to identify children with global sleep disorders [31, 32]. For each of 8 subscale scores, a subscale score $>1 \mathrm{SD}$ above the mean subscale score of the published control sample was considered to be clinically significant $[30,33]$.

In addition, evening bedtime and wake-up time for weekdays and weekends were also collected. The calculation formula for average sleep duration was calculated as follows: [(weekday sleep duration $\times 5)+($ weekend sleep duration $\times 2)] / 7[10]$.

\section{Statistical analysis}

Data analyses were performed using the IBM Statistical Package for the Social Sciences statistics for Windows (V.13.0, Armonk, NY, USA). For eye-specific measurement, only data from the right eye of each participant were included for analysis. Continuous data were presented as mean and standard deviation (SD). Independent two sample T-test was used to compare means and chi-squared test was used to compare proportions. Univariable linear regression model was used to evaluate the association between each candidate factors and SFCT. Factors with $P$ value $<0.20$ in univariable analysis were included in the multivariable linear regression for backward variable selection, and the final multivariable regression model evaluating the association of overall total CSHQ score and SFCT was adjusted by risk factors with $p<0.05$ along with age and gender. Similar analyses were performed for evaluating association of each subscale of CSHQ score with SFCT by including the same risk factors as model for evaluating total CSHQ score. Standardised regression coefficients from the regression models are presented with $95 \%$ confidence intervals $(95 \% \mathrm{CI})$. Two-sided $P$ values $<0.05$ were considered statistically significant.

\section{Results}

Among 2300 eligible children, 1920 (response rate $83.48 \%$ ) participated in the study and 583 were excluded because of incomplete ocular examinations or poor quality of OCT images. The children excluded were not different from the included children in age, gender or other characteristics (see Supplementary sTable 1). Among 1337 children included in the analysis, the mean (SD) age was 66.88 (3.41) months and $45.5 \%(n=609)$ were girls. The mean (SD) SFCT was $307.41(63.42) \mu \mathrm{m}$. The mean (SD) sleep duration was $9.99(0.64) \mathrm{h}$ per day. Among all participants, the CSHQ total score ranged 33 to 70 , with mean (SD) of CSHQ total score 47.33 (5.13). $88.8 \%$ (1187/1337) children had total CSHQ score above 41 (the cut-off for global sleep disorder). The characteristics of the participants were shown in Table 1.

Associations of SFCT and its candidate risk factors were shown in Table 2. In univariable linear regression, SFCT was significantly associated with gender, SE, AL and CR $(P<0.05)$, and marginally associated with total CSHQ scores $(P=0.05)$. In multivariable linear regression, SFCT was significantly associated with total CSHQ score $(P=$ 0.046) after adjusting for age, gender, height, birthweight and AL. The standardised regression coefficient from the multivariable regression model was -0.070 (95\% CI: -0.141 to -0.001$)$, suggesting more sleep disorder was associated with thinner SFCT. 
Table 1 Characteristics of the 1337 participants.

\begin{tabular}{lc}
\hline Parameters & Mean (SD)/number (\%) \\
\hline Age, $m$ & $66.88(3.41)$ \\
Gender (girls), \% & $609(45.5)$ \\
SFCT, $\mu \mathrm{m}$ & $307.41(63.42)$ \\
Height, cm & $111.27(7.57)$ \\
Weight, kg & $19.91(4.08)$ \\
Body mass index, kg/m ${ }^{2}$ & $15.94(1.80)$ \\
Birthweight, kg & $3.32(0.54)$ \\
Spherical equivalent, D & $1.18(0.93)$ \\
Axial length, mm & $22.49(0.71)$ \\
Central corneal thickness, $\mu \mathrm{m}$ & $541.44(31.25)$ \\
Anterior chamber depth, mm & $2.82(0.25)$ \\
Lens thickness, mm & $3.69(0.22)$ \\
Corneal radius of curvature, mm & $7.83(0.25)$ \\
Outdoor activities, h/w & $15.55(7.85)$ \\
Dioptre-hour, h/w & $75.94(68.00)$ \\
Sleep duration, h/d & $9.99(0.64)$ \\
CSHQ score & $47.33(5.13)$ \\
Father with myopia, \% & $472(35.3)$ \\
Mother with myopia, \% & $515(38.5)$ \\
Father with high school or below, \% & $682(51.0)$ \\
Mother with high school or below, \% & $710(53.1)$ \\
Pre-term history, \% & $64(4.8)$ \\
Maternal second-hand smoking exposure & $189(14.1)$ \\
when pregnancy, \% & \\
\hline sF & \\
\hline
\end{tabular}

SFCT subfoveal choroidal thickness, $C H S Q$ score the score of Children's Sleep Habits Questionnaire.

When each of eight CSHQ subscale scores was analysed using the multivariable model separately instead of total CSHQ score, only the Daytime Sleepiness subscale score was found to be negatively associated with choroidal thickness (beta, $-0.115, P=0.001$, Table 3) after adjusting for age, gender, height, $\mathrm{AL}$ and birthweight. Approximately $27.2 \%$ (364/1337) children scored more than 1 SD above the published normative mean in the Daytime Sleepiness subscale (i.e. above 12.44) and were considered to have clinically significant daytime sleepiness. In children with clinically significant daytime sleepiness, SFCT was 13.05 $\mu \mathrm{m}$ thinner compared to children without this problem $(295.47 \mu \mathrm{m}$ vs. $308.52 \mu \mathrm{m}, P=0.007$, Table 4$)$, after adjusting for age, gender, height, AL and birthweight.

\section{Discussion}

Our study found that higher total CSHQ score (indicating higher likelihood of more sleep problems) was associated with thinner subfoveal choroid in children aged 60-72 months after adjusting for other confounding factors.
More specifically, among the eight CSHQ subscale scores, only the Daytime Sleepiness subscale score was negatively associated with SFCT. Children with clinically significant daytime sleepiness had $13.05 \mu \mathrm{m}$ thinner subfoveal choroid than these without this sleep disorder.

Our study used the CSHQ to evaluate the sleep habits of participants. The CSHQ is one of the most common used instruments to screen sleep disorders among children aged 4-10 years [30]. It is designed on the basis of the International Classification of Sleep Disorders: Diagnostic and Coding Manual and can target common sleep disorder symptoms in children [34]. The validity of this questionnaire has been evaluated in more than 200 studies all over the world, and it has been cited in over 600 articles and translated into many languages $[28,35]$. The reliability and validity of the Chinese version of the CSHQ we used have been verified in several studies [27-29]. Thus, we believe that CSHQ can provide valid data of sleep habits of our study participants for evaluating its association with SFCT. In this study, $88.8 \%$ participants had sleep disorder (CSHQ score $>41$ ), which is consistent with a previous study conducted in Chinese preschool children using the CSHQ questionnaire [31].

Of 8 subscales of the CSHQ, we only found daytime sleepiness was associated with SFCT. Daytime sleepiness is an easily ignored sleep disorder in children. According to a community-based research in children aged 5-12 years, the prevalence of parent or teacher-reported daytime sleepiness was nearly $15 \%$ [36]. In our study, about $27 \%$ children had clinically significant daytime sleepiness measured by CSHQ. The primary cause of daytime sleepiness among children is insufficient sleep, which is often related with poor sleep hygiene [37]. Besides, some diseases may result in daytime sleepiness, such as OSAS, periodic limb movement, restless leg syndrome, narcolepsy, Kleine-Levin syndrome and so on [5]. Previous studies suggested that children with daytime sleepiness were more likely to have impairments in functional areas, including behaviour, mood, and performance [38]. Our study provides evidence that daytime sleepiness may be related with changes in ocular choroidal structure in children. Although insufficient sleep is the main cause of daytime sleepiness, we failed to find associations between sleep duration and SFCT. This may be due to the fact that sleep duration reported by parents is just the period from bedtime to time to get up and does not necessarily represent the actual amounts of sleep in children. Delayed sleep onset latency, frequent night awakenings and other factors that may impair sleep quality can also cause insufficient sleep.

Our study found that in children with clinically significant daytime sleepiness, SFCT was $13.05 \mu \mathrm{m}$ thinner compared to children without this problem. This magnitude of difference in SFCT is clinically significant 
Table 2 Univariable and multivariable analyses for associations between all potential factors and SFCT.

\begin{tabular}{|c|c|c|c|c|}
\hline \multirow[t]{2}{*}{ Parameters } & \multicolumn{2}{|l|}{ Univariable analysis } & \multicolumn{2}{|l|}{ Multivariable analysis $^{\mathrm{a}}$} \\
\hline & $\mathrm{B}^{\mathrm{b}}(95 \% \mathrm{CI})$ & $P$ & $\mathrm{~B}(95 \% \mathrm{CI})$ & $P$ \\
\hline Age, $m$ & $0.039(-0.019,0.096)$ & 0.19 & $0.042(-0.030,0.111)$ & 0.26 \\
\hline \multicolumn{5}{|l|}{ Gender } \\
\hline Boys & Ref & & Ref & \\
\hline Girls & $0.091(0.034,0.149)$ & 0.002 & $0.056(-0.019,0.129)$ & 0.14 \\
\hline Height, cm & $-0.059(-0.118,0.001)$ & 0.06 & $-0.094(-0.165,-0.020)$ & 0.01 \\
\hline Weight, $\mathrm{kg}$ & $-0.047(-0.105,-0.012)$ & 0.12 & & \\
\hline Body mass index, $\mathrm{kg} / \mathrm{m}^{2}$ & $-0.025(-0.084,0.034)$ & 0.41 & & \\
\hline Birthweight, kg & $0.055(-0.012,0.120)$ & 0.11 & $0.101(0.028,0.165)$ & 0.006 \\
\hline Spherical equivalent, D & $0.077(0.020,0.139)$ & 0.009 & & \\
\hline Axial length, mm & $-0.171(-0.232,-0.116)$ & $<0.001$ & $-0.155(-0.236,-0.078)$ & $<0.001$ \\
\hline Central corneal thickness, $\mu \mathrm{m}$ & $-0.044(-0.099,0.013)$ & 0.14 & & \\
\hline Anterior chamber depth, mm & $-0.006(-0.064,0.052)$ & 0.84 & & \\
\hline Lens thickness, mm & $0.035(-0.024,0.095)$ & 0.24 & & \\
\hline Corneal radius of curvature, $\mathrm{mm}$ & $-0.136(-0.195,-0.080)$ & $<0.001$ & & \\
\hline Outdoor activities, h/w & $0.029(-0.039,0.096)$ & 0.40 & & \\
\hline Dioptre-hour, h/w & $-0.017(-0.080,0.047)$ & 0.62 & & \\
\hline Sleep duration, $\mathrm{h} / \mathrm{d}$ & $-0.052(-0.120,0.015)$ & 0.13 & & \\
\hline CSHQ score & $-0.066(-0.136,0.001)$ & 0.05 & $-0.070(-0.141,-0.001)$ & 0.046 \\
\hline \multicolumn{5}{|l|}{ Father with myopia } \\
\hline Yes & $0.002(-0.064,0.069)$ & 0.95 & & \\
\hline No & Ref & & & \\
\hline \multicolumn{5}{|l|}{ Mother with myopia } \\
\hline Yes & $0.006(-0.061,0.073)$ & 0.86 & & \\
\hline No & Ref & & & \\
\hline \multicolumn{5}{|l|}{ Father education level } \\
\hline High school or below & $-0.044(-0.111,0.023)$ & 0.20 & & \\
\hline University degree or above & Ref & & & \\
\hline \multicolumn{5}{|l|}{ Mother education level } \\
\hline High school or below & $-0.035(-0.101,0.032)$ & 0.31 & & \\
\hline University degree or above & Ref & & & \\
\hline \multicolumn{5}{|l|}{ Pre-term history } \\
\hline Yes & $-0.064(-0.130,0.003)$ & 0.06 & & \\
\hline No & Ref & & & \\
\hline \multicolumn{5}{|c|}{ Maternal second-hand smoking exposure when pregnancy } \\
\hline Yes & $-0.010(-0.078,0.057)$ & 0.77 & & \\
\hline No & Ref & & & \\
\hline
\end{tabular}

Bold values indicate statistical significance $p \leq 0.05$.

$S F C T$ subfoveal choroidal thickness, $C H S Q$ score the score of Children's Sleep Habits Questionnaire, Ref reference group.

${ }^{a}$ The multivariable model was adjusted for age, gender, AL, height and birthweight.

${ }^{\mathrm{b}}$ The regression coefficient B is standardised regression coefficient. compared with previous studies, which found that one dioptre toward myopia was associated with a decrease of $10 \mu \mathrm{m}$ in central foveal choroidal thickness and child exposure to second-hand smoking was associated with a decrease of $8.3 \mu \mathrm{m}$ in central foveal choroidal thickness
$[39,40]$. Therefore, more attention should be paid to the sleep hygiene in children.

In adults, the change of choroidal thickness was only explored in one kind of sleep disorders, that is, OSAS. In a meta-analysis performed to evaluate the choroidal thickness 
Table 3 The associations between CSHQ subscale scores and SFCT.

\begin{tabular}{|c|c|c|c|c|c|}
\hline \multirow[t]{2}{*}{ Subscale scores } & \multirow[t]{2}{*}{ Mean (SD) } & \multicolumn{2}{|l|}{ Univariable analysis } & \multicolumn{2}{|l|}{ Multivariable analysis ${ }^{\mathrm{a}}$} \\
\hline & & $\mathrm{B}^{\mathrm{b}}(95 \% \mathrm{CI})$ & $P$ & B $(95 \% \mathrm{CI})$ & $P$ \\
\hline Bedtime resistance & $10.91(1.97)$ & $-0.038(-0.104,0.029)$ & 0.27 & & \\
\hline Sleep onset delay & $2.21(0.75)$ & $0.017(-0.049,0.084)$ & 0.61 & & \\
\hline Sleep duration & $5.85(1.20)$ & $-0.007(-0.074,0.060)$ & 0.85 & & \\
\hline Sleep anxiety & $6.42(1.98)$ & $-0.064(-0.130,0.003)$ & 0.06 & & \\
\hline Night wakings & $3.32(0.69)$ & $-0.044(-0.116,0.024)$ & 0.20 & & \\
\hline Parasomnias & $7.83(1.17)$ & $-0.009(-0.080,0.061)$ & 0.80 & & \\
\hline $\begin{array}{l}\text { Sleep disordered } \\
\text { breathing }\end{array}$ & $3.35(0.73)$ & $0.028(-0.039,0.096)$ & 0.41 & & \\
\hline Daytime sleepiness & $11.30(2.10)$ & $-0.098(-0.166,-0.031)$ & 0.004 & $-0.115(-0.183,-0.046)$ & 0.001 \\
\hline
\end{tabular}

Bold values indicate statistical significance $p \leq 0.05$.

$S F C T$ subfoveal choroidal thickness, $C H S Q$ score the score of Children's Sleep Habits Questionnaire.

${ }^{a}$ The multivariable model was adjusted for age, gender, AL, height and birthweight.

${ }^{\mathrm{b}}$ The regression coefficient $\mathrm{B}$ is standardised regression coefficient.

Table 4 The associations between clinically significant subscales and SFCT.

\begin{tabular}{|c|c|c|c|c|c|c|c|c|}
\hline \multirow[t]{2}{*}{ Subscales } & \multirow{2}{*}{$\begin{array}{l}\text { Cut-off } \\
\text { values }^{\text {a }}\end{array}$} & \multirow{2}{*}{$\begin{array}{l}\text { Clinically } \\
\text { significant }\end{array}$} & \multirow[t]{2}{*}{ Number } & \multicolumn{2}{|l|}{ Univariable analysis } & \multicolumn{3}{|l|}{ Multivariable analysis ${ }^{\mathrm{b}}$} \\
\hline & & & & $\mathrm{B}^{\mathrm{c}}(95 \% \mathrm{CI})$ & $P$ & $\begin{array}{l}\text { Adjusted mean } \\
(95 \% \mathrm{CI})\end{array}$ & B $(95 \%$ CI $)$ & $P$ \\
\hline \multirow{2}{*}{$\begin{array}{l}\text { Bedtime } \\
\text { resistance }\end{array}$} & 8.95 & Yes & 1197 & $-0.042(-0.107,0.025)$ & 0.23 & & & \\
\hline & & No & 140 & Ref & & & & \\
\hline \multirow{2}{*}{$\begin{array}{l}\text { Sleep } \\
\text { onset delay }\end{array}$} & 1.78 & Yes & 1072 & $0.038(-0.029,0.105)$ & 0.27 & & & \\
\hline & & No & 265 & Ref & & & & \\
\hline \multirow[t]{2}{*}{ Sleep duration } & 4.34 & Yes & 1182 & $-0.017(-0.083,0.050)$ & 0.62 & & & \\
\hline & & No & 155 & Ref & & & & \\
\hline \multirow[t]{2}{*}{ Sleep anxiety } & 6.34 & Yes & 578 & $-0.059(-0.126,0.008)$ & 0.09 & & & \\
\hline & & No & 759 & Ref & & & & \\
\hline \multirow[t]{2}{*}{ Night wakings } & 4.40 & Yes & 118 & $-0.055(-0.130,0.013)$ & 0.11 & & & \\
\hline & & No & 1219 & Ref & & & & \\
\hline \multirow[t]{2}{*}{ Parasomnias } & 9.36 & Yes & 116 & $0.015(-0.054,0.083)$ & 0.67 & & & \\
\hline & & No & 1221 & Ref & & & & \\
\hline \multirow{2}{*}{$\begin{array}{l}\text { Sleep } \\
\text { disordered } \\
\text { breathing }\end{array}$} & 3.87 & Yes & 325 & $0.035(-0.032,0.102)$ & 0.31 & & & \\
\hline & & No & 1012 & Ref & & & & \\
\hline \multirow{2}{*}{$\begin{array}{l}\text { Daytime } \\
\text { sleepiness }\end{array}$} & 12.44 & Yes & 364 & $-0.078(-0.144,-0.011)$ & 0.02 & $295.47(287.42,303.51)$ & $-0.094(-0.159,-0.025)$ & 0.007 \\
\hline & & No & 973 & Ref & & $308.52(303.52,313.51)$ & & \\
\hline
\end{tabular}

Bold values indicate statistical significance $p \leq 0.05$.

$S F C T$ subfoveal choroidal thickness, Ref reference group.

${ }^{a}$ Cut-off value is $1 \mathrm{SD}$ above the mean score of the published control sample.

${ }^{\mathrm{b}}$ The multivariable model was adjusted for age, gender, AL, height and birthweight.

${ }^{\mathrm{c}}$ The regression coefficient $\mathrm{B}$ is standardised regression coefficient.

changes in OSAS, SFCT was significantly reduced compared with normal controls, with mean difference of -8.06 to $-53.72 \mu \mathrm{m}$ for mild to severe OSAS [15]. Although the exact mechanism for this association remains unclear, it is speculated that intermittent airway obstruction in OSAS causes recurrent hypoxia and reperfusion, which leads to 
oxidative stress and inflammation, vascular endothelium damage, impaired responsiveness to vasodilator agents, and activated sympathetic system [41]. The series of changes result in decreased choroidal blood flow, and therefore reduced choroidal thickness. As mentioned above, OSAS can cause daytime sleepiness in children, so it can be one of the underlying mechanisms for the thinner SFCT in children with daytime sleepiness.

As the prevalence of OSAS is only from 1.2 up to $5 \%$ in children [42, 43], there must be other reasons for explaining our significant association between sleep disorders and SFCT. Most daytime sleepiness is caused by insufficient sleep, associated with poor sleep hygiene such as irregular sleep schedules, electronics use before bed, and vigorous play before bed [44]. These behaviours can interfere with circadian sleep-wake rhythm among children and contribute to irregular secretion of melatonin [12]. As a neurohormone, melatonin can act directly on many ocular structures to mediate various circadian rhythms and physiological processes in the eye [45]. Melatonin receptors are also present in the choroid [46]. It has been found in animal experiments that systemic administration of melatonin resulted in significant changes in choroidal thickness [47]. Therefore, the association between choroidal thickness and daytime sleepiness may be due to changes in melatonin secretion, which affects the normal growth of the choroid.

We did not find the association between the sleep disordered breathing subscale and SFCT. This might be due to, among children who scored high in the sleep disordered breathing subscale, only a small number (1 'usually', 2 'sometimes') had the problem of stopping breathing in sleep and were likely to have OSAS. Besides, the sleep disordered breathing might interfere less with circadian rhythm than the daytime sleepiness. In addition, other subscales of CSHQ were not associated with SFCT in our study, which might be because of their not close relationship with OSAS and circadian rhythm. The borderline association between the overall sleep questionnaire and SFCT might be due to that no relationship between the seven subscales and SFCT was found. However, further research is needed to clarify why only daytime sleepiness subscale was related with SFCT.

There are few studies for choroidal thickness in preschool children younger than 6 years old, partially due to the difficulty in obtaining good OCT images from these young children. To obtain reliable measurement of choroidal thickness, this study only included participants with choroidal OCT images of high quality in a large populationbased sample. In addition, all choroidal images in this study were obtained before pupil dilation and in a similar time period within a day, which further eliminated possible factors affecting choroidal thickness [48, 49]. Besides, we included more than 20 possible confounders in the linear regression analyses, which raises the accuracy of our results.

Our study still has some limitations. First, sleep disorders were assessed by parents through questionnaires, which may have recall bias. Objective measures of children's sleep behaviour, like polysomnography and actigraphy, may produce highly reliable and valid data. However, the cost, time, and effort associated with these measures make them difficult to implement in epidemiological investigations like our study. Second, about $16.5 \%$ children refused to participate in our study and we excluded some participants from analysis because of incomplete ocular examinations or poor quality of OCT images, which may lead to the biased estimate of association. Third, we only measured SFCT in this study, and the associations between sleep disorders and choroidal thickness in other sectors are unknown. Nevertheless, complex scan pattern needed to collect the choroidal images in different sectors is time-consuming, thus difficult to carry out in preschool children because they cannot keep fixation for a long time. Fourth, like other cross-sectional studies, we could not make any causal inference for the association between daytime sleepiness and SFCT. In addition, only daytime sleepiness subscale was found to be related with SFCT among the 8 subscales and the association between the overall sleep questionnaire score and SFCT was marginal. The results of this exploratory study need more replications and verifications. Fifth, $4.8 \%$ of our participants had a pre-term history, which might have an influence on the results. However, the association between CSHQ score and SFCT still existed after including pre-term history in the multivariable model (see sTable 2). Finally, the association between daytime sleepiness and SFCT found in our study might be due to the possible relationship between sleep disorders and myopia (characterised by decreased choroidal thickness), which was reported in several previous studies [21, 50]. However, AL and SE were adjusted for in the multivariable analysis (see Table 2). Besides, we failed to find an association between sleep disorders and SE or AL (see sTables 3, 4), which was consistent to the findings in recent studies [51, 52]. More research may be warranted to clarify the potentially triangular relationship between sleep disorders, myopia, and choroidal thickness.

\section{Conclusions}

In this cross-sectional population-based study, we found that daytime sleepiness was significantly associated with SFCT in children aged 60-72 months after adjusting for confounding factors. Children with clinically significant daytime sleepiness had $13.05 \mu \mathrm{m}$ thinner SFCT compared to children without this sleep disorder. Although this finding 
cannot prove a causative relationship and the exact mechanism remains unknown, this study provides important information that, daytime sleepiness, a common sleep disorder in modern society, is associated with altered ocular health in early childhood.

\section{Summary}

\section{What was known before}

- Sleep disorders were very common in children, and have been acknowledged to be associated with numerous impairments and diseases.

- Choroid is the main source of ocular blood flow and is important for ocular development and health. Adults with obstructive sleep apnoea syndrome (OSAS) have been reported to have reduced SFCT.

- The effect of sleep disorders on children's choroidal thickness remains unknown.

\section{What this study adds}

- We found that more daytime sleepiness in preschool children was associated with subfoveal choroidal thinning, which is independent of the known factors that influence choroidal thickness.

- Sleep disorder is associated with altered ocular health in early childhood.

- Daytime sleepiness warrants early recognition and management.

\begin{abstract}
Acknowledgements We thank the children, their parents or legal guardians, and all the members of the Maternal and Child Healthcare Hospital of Yuhuatai District, Nanjing, China, for their helpful advice and support.
\end{abstract}

Author contributions HL and HZ were responsible for conception, design and critical revision of the paper. SYS, XXL, RL, HZ and HL were responsible for drafting of the paper, extracting and analysing data, interpreting results, updating reference lists and creating tables. SYS, XXL, RL, HZ, DH, XYZ, XHZ, QFH, QGS, HHT, XYZ, YLZC and SNL were responsible for acquisition, analysis and interpretation of data.

Funding The work was supported by National Natural Science Foundation of China (Grant No. 81673198; No. 81803258); Natural Science Foundation of Jiangsu Province (Grant No. BK20161595). The funders had no role in the design of the study, collection and analysis of data and decision to publish.

\section{Compliance with ethical standards}

Conflict of interest The authors declare no competing interests.
Publisher's note Springer Nature remains neutral with regard to jurisdictional claims in published maps and institutional affiliations.

Open Access This article is licensed under a Creative Commons Attribution 4.0 International License, which permits use, sharing, adaptation, distribution and reproduction in any medium or format, as long as you give appropriate credit to the original author(s) and the source, provide a link to the Creative Commons license, and indicate if changes were made. The images or other third party material in this article are included in the article's Creative Commons license, unless indicated otherwise in a credit line to the material. If material is not included in the article's Creative Commons license and your intended use is not permitted by statutory regulation or exceeds the permitted use, you will need to obtain permission directly from the copyright holder. To view a copy of this license, visit http://creativecommons. org/licenses/by/4.0/.

\section{References}

1. Moturi S, Avis K. Assessment and treatment of common pediatric sleep disorders. Psychiatry. 2010;7:24.

2. Steinsbekk S, Berg-Nielsen TS, Wichstrøm L. Sleep disorders in preschoolers: prevalence and comorbidity with psychiatric symptoms. J Dev Behav Pediatr. 2013;34:633-41.

3. Friedman NP, Corley RP, Hewitt JK, Wright KJ. Individual differences in childhood sleep problems predict later cognitive executive control. Sleep. 2009;32:323-33.

4. Owens J. Classification and epidemiology of childhood sleep disorders. Prim Care. 2008;35:533-46.

5. Moreira GA, Pradella-Hallinan M. Sleepiness in children. Sleep Med Clin. 2017;12:407-13.

6. Beebe DW. Cognitive, behavioral, and functional consequences of inadequate sleep in children and adolescents. Pediatr Clin N Am. 2011;58:649-65.

7. Owens JA, Fernando S, Mc Guinn M. Sleep disturbance and injury risk in young children. Behav Sleep Med. 2005;3:18-31.

8. Whalen DJ, Gilbert KE, Barch DM, Luby JL, Belden AC. Variation in common preschool sleep problems as an early predictor for depression and anxiety symptom severity across time. J Child Psychol Psychiatry. 2017;58:151-9.

9. Meltzer LJ, Mindell JA. Sleep and sleep disorders in children and adolescents. Psychiatr Clin N Am. 2006;29:1059-76.

10. Wang J, Adab P, Liu W, Chen Y, Li B, Lin R, et al. Prevalence of adiposity and its association with sleep duration, quality, and timing among 9-12-year-old children in Guangzhou, China. J Epidemiol. 2017;27:531-7.

11. Jee HJ, Shin W, Jung HJ, Kim B, Lee BK, Jung Y. Impact of sleep disorder as a risk factor for dementia in men and women. Biomol Ther. 2020;28:58-73.

12. Xie Z, Chen F, Li WA, Geng X, Li C, Meng X, et al. A review of sleep disorders and melatonin. Neurol Res. 2017;39:559-65.

13. Read SA, Fuss JA, Vincent SJ, Collins MJ, Alonso Caneiro D. Choroidal changes in human myopia: insights from optical coherence tomography imaging. Clin Exp Optom. 2019;102:270-85.

14. Tan K, Gupta PM, Agarwal AM, Chhablani JM, Cheng CP, Keane PAF, et al. State of science: choroidal thickness and systemic health. Surv Ophthalmol. 2016;61:566-81.

15. He M, Han X, Wu H, Huang W. Choroidal thickness changes in obstructive sleep apnea syndrome: a systematic review and metaanalysis. Sleep Breath. 2016;20:369-78.

16. Song Y, Tham Y, Chong C, Ong R, Fenner BJ, Cheong KX, et al. Patterns and determinants of choroidal thickness in a multiethnic asian population: the Singapore epidemiology of eye diseases study. Ophthalmol Retina. 2020. https://doi.org/10.1016/j.oret.2020.08.012. 
17. Wong CW, Teo YCK, Tsai STA, Ting SWD, Yeo YSI, Wong WKD, et al. Characterization of the choroidal vasculature in myopic maculopathy with optical coherence tomographic angiography. Retina. 2019;39:1742-50.

18. Troilo D, Smith ER, Nickla DL, Ashby R, Tkatchenko AV, Ostrin LA, et al. IMI-Report on experimental models of emmetropization and myopia. Investig Ophthalmol Vis Sci. 2019;60: M31-88.

19. Wu Q, Chen Q, Lin B, Huang S, Wang Y, Zhang L, et al. Relationships among retinal/choroidal thickness, retinal microvascular network and visual field in high myopia. Acta Ophthalmol. 2020;98:e709-14.

20. Xiong S, He X, Zhang B, Deng J, Wang J, Lv M, et al. Changes in choroidal thickness varied by age and refraction in children and adolescents: a 1-year longitudinal study. Am J Ophthalmol. 2020; 213:46-56.

21. Zhou Z, Morgan IG, Chen Q, Jin L, He M, Congdon N. Disordered sleep and myopia risk among chinese children. Plos ONE. 2015;10:e121796.

22. Zhao $\mathrm{X}$, Li R, Huang $\mathrm{D}$, Tong $\mathrm{H}$, Zhu $\mathrm{H}$, Wang $\mathrm{Y}$, et al. Decreased retinal thickness in preschool offspring of maternal gestational hypertension: the Nanjing Eye Study. Acta Ophthalmol. 2020;98:e674-9.

23. Wang Z, Huang D, Chen X, Zhu H, Sun Q, Wang Y, et al. Preschool children exhibit evident compensatory role of internal astigmatism in distribution of astigmatism: the Nanjing Eye Study. Investig Ophthalmol Vis Sci. 2019;60:73-81.

24. Zhang X, Wang Y, Huang D, Sun Q, Zhao X, Ding H, et al. Prevalence of reduced visual acuity among preschool children in eastern China and comparison at a 5-year interval. Clin Exp Ophthalmol. 2018;46:994-1001.

25. Jones LA, Sinnott LT, Mutti DO, Mitchell GL, Moeschberger ML, Zadnik K. Parental history of myopia, sports and outdoor activities, and future myopia. Investig Opthalmol Vis Sci. 2007;48:3524.

26. Mutti DO, Mitchell GL, Moeschberger ML, Jones LA, Zadnik K. Parental myopia, near work, school achievement, and children's refractive error. Investig Ophthalmol Vis Sci. 2002;43:3633-40.

27. Wang G, Xu G, Liu Z, Lu N, Ma R, Zhang E. Sleep patterns and sleep disturbances among Chinese school-aged children: prevalence and associated factors. Sleep Med. 2013;14:45-52.

28. Li Y, Jin H, Owens JA, Hu C. The association between sleep and injury among school-aged children in rural China: a case-control study. Sleep Med. 2008;9:142-8.

29. Liu X, Liu L, Wang R. Bed sharing, sleep habits, and sleep problems among Chinese school-aged children. Sleep. 2003;26: 839-44.

30. Owens JA, Spirito A, McGuinn M. The children's sleep habits questionnaire (CSHQ): psychometric properties of a survey instrument for school-aged children. Sleep. 2000;23:1043-9.

31. Wang G, Takahashi M, Wu R, Liu Z, Adachi M, Saito M, et al. Association between sleep disturbances and emotional/behavioral problems in chinese and japanese preschoolers. Behav Sleep Med. 2020;18:420-31.

32. Takahashi M, Wang G, Adachi M, Jiang Y, Jiang F, Saito M, et al. Differences in sleep problems between Japanese and Chinese preschoolers: a cross-cultural comparison within the Asian region. Sleep Med. 2018;48:42-8.

33. Markovich AN, Gendron MA, Corkum PV. Validating the children's sleep habits questionnaire against polysomnography and actigraphy in school-aged children. Front Psychiatry. 2015;5:188.

34. International Classification of Sleep Disorders. Diagnostic and coding manual. Diagnostic classification steering committee.
Thorpy MJ,Chairman. Rochester, MN: American Sleep Disorder Association; 1990.

35. Liu Z, Wang G, Geng L, Luo J, Li N, Owens J. Sleep patterns, sleep disturbances, and associated factors among Chinese urban kindergarten children. Behav Sleep Med. 2016;14:100-17.

36. Calhoun SL, Vgontzas AN, Fernandez-Mendoza J, Mayes SD, Tsaoussoglou M, Basta M, et al. Prevalence and risk factors of excessive daytime sleepiness in a community sample of young children: the role of obesity, asthma, anxiety/depression, and sleep. Sleep. 2011;34:503-7.

37. Marcus CL. Daytime sleepiness in children: When a quiet child is not necessarily a good thing. Paediatr Respir Rev. 2018; 25:1-2.

38. Fallone G, Owens JA, Deane J. Sleepiness in children and adolescents: clinical implications. Sleep Med Rev. 2002;6:287-306.

39. Yuan N, Li J, Tang S, Li FF, Lee CO, Ng MPH, et al. Association of secondhand smoking exposure with choroidal thinning in children aged 6 to 8 years. Jama Ophthalmol. 2019;137:1406.

40. Jin P, Zou H, Zhu J, Xu X, Jin J, Chang TC, et al. Choroidal and retinal thickness in children with different refractive status measured by swept-source optical coherence tomography. Am J Ophthalmol. 2016;168:164-76.

41. Marin JM, Carrizo SJ, Vicente E, Agusti AG. Long-term cardiovascular outcomes in men with obstructive sleep apnoeahypopnoea with or without treatment with continuous positive airway pressure: an observational study. Lancet. 2005;365: 1046-53.

42. Bixler EO, Vgontzas AN, Lin H, Liao D, Calhoun S, Vela-Bueno A, et al. Sleep disordered breathing in children in a general population sample: prevalence and risk factors. Sleep. 2009;32:731-6.

43. Marcus CL, Brooks LJ, Draper KA, Gozal D, Halbower AC, Jones J, et al. Diagnosis and management of childhood obstructive sleep apnea syndrome. Pediatrics. 2012;130:576-84.

44. Thomas JH, Burgers DE. Sleep is an eye-opener: Behavioral causes and consequences of hypersomnolence in children. Paediatr Respir Rev. 2018;25:3-8.

45. Ostrin LA. Ocular and systemic melatonin and the influence of light exposure. Clin Exp Optom. 2019;102:99-108.

46. Alarma-Estrany P, Pintor J. Melatonin receptors in the eye: location, second messengers and role in ocular physiology. Pharmacol Ther. 2007;113:507-22.

47. Rada JAS, Wiechmann AF. Melatonin receptors in chick ocular tissues: implications for a role of melatonin in ocular growth regulation. Investig Ophth Vis Sci. 2006;47:25.

48. Sander BP, Collins MJ, Read SA. The effect of topical adrenergic and anticholinergic agents on the choroidal thickness of young healthy adults. Exp Eye Res. 2014;128:181-9.

49. Tan CS, Ouyang Y, Ruiz H, Sadda SR. Diurnal variation of choroidal thickness in normal, healthy subjects measured by spectral domain optical coherence tomography. Investig Ophthalmol Vis Sci. 2012;53:261-6.

50. Chakraborty R, Micic G, Thorley L, Nissen TR, Lovato N, Collins $\mathrm{MJ}$, et al. Myopia, or near-sightedness, is associated with delayed melatonin circadian timing and lower melatonin output in young adult humans. Sleep. 2020;zsaa208. https://doi.org/10.1093/sleep/ zsaa208.

51. Pan C, Liu J, Wu R, Zhong H, Li J. Disordered sleep and myopia among adolescents: a propensity score matching analysis. Ophthal Epidemiol. 2019;26:155-60.

52. Wei S, Li S, Liu L, Li H, Kang M, Sun Y, et al. Sleep duration, bedtime, and myopia progression in a 4-year follow-up of Chinese children: the Anyang Childhood Eye Study. Investig Ophth Vis Sci. 2020;61:37. 